\title{
Correlates of Index Futures and Spot Index Volatility: A Study of Indian Stock Market
}

\author{
Dr. Khurshid Ali Ganai \\ Assistant Professor \\ Higher Colleges of Technology \\ Abu Dhabi, United Arab Emirates
}

\begin{abstract}
In this paper an analysis on the dynamic relationship between Index Futures and Spot Index Volatility is carried out to ascertain the extent of influence that Index Futures hold over underlying (spot index). For this purpose relevant intraday data from $1^{\text {st }}$ April $1998-31^{\text {st }}$ March 2000 of S\&P CNX NIFTY (50) are used to measure the level of volatility of spot Index during the pre-derivatives period. The second reference period is taken from $1^{\text {st }}$ 0ctober $2000-30^{\text {th }}$ September 2002 to determine the level of volatility during the post-derivatives period. This is followed by a comparative analysis of both the periods and the findings put forth by the comparison affirms that there exists a significant correlation between index futures and underlying volatility (Spot Index) as the level of the volatility throughout the post-derivatives period has had a considerable decline. The findings of this study collaborate and strengthen the results of many studies mentioned in the review.
\end{abstract}

Key Words: Spot Index, Index Futures, Volatility, Derivatives and Underlying.

\section{INTRODUCTION}

Ever since the willingness of risk-averse economic agents, to guard themselves against uncertainties arising out of fluctuations in the asset prices, led a unique system to grow slowly all over the business world, known as derivatives in the modern terminology. For centuries these derivatives contracts were used exhaustively in the agriculture markets. The primary motivation for pre-arranging a buyer/seller for the stock of a commodity, in the early forwards contracts, was to lessen the possibility that large swing would inhibit marketing the commodity after the harvest. Therefore, these products initially emerged as hedging devices against fluctuations in commodity prices. These commodity-linked derivatives remained the sole form of hedging almost centuries together. Earlier, derivatives products in the U.S.A. addressed merchants' concern about ensuring that they were the buyers and sellers for commodities, however, "credit-risk" remained a serious problem. In order to deal with this problem, a group of Chicago businessmen formed "Chicago Board of Trade" (CBOT) in 1848. The primary intention of CBOT was to provide a centralised location in advance to the buyers and sellers so as to negotiate forward contracts. In 1865 the Chicago Board of Trade (CBOT) went one more step forward and listed the first "Exchange Traded Derivatives Contract" in the USA. These contracts were called "Futures Contracts" and in 1919 Chicago Butter and Egg Board, a spin-off of CBOT, was recognised to allow futures trading. Later, its name was changed to Chicago Mercantile Exchange (CME). The Chicago Board of Trade (CBOT) and the Chicago Mercantile Exchange (CME) remain the two largest futures exchanges, indeed the two largest "Financial Exchanges" of any kind in the world today.

Financial derivatives, most notably forwards, futures and options came into spot-light in the post-1970s period due to growing instability in the financial markets which was the reflection of high volatility in exchange rates and interest rates. Through the use of derivatives, it has 
been possible to partially or fully transfer the risk by locking-in the asset prices. The first stock index futures contract was traded at Kansas City Board of Trade. In the class of equity derivatives the world over, futures and options on stock indices have gained significant popularity than on individual stocks, especially among institutional investors, who are major players of index-linked derivatives, even small investors find these useful due to high correlation of the popular indices with various portfolio.

The first step towards the introduction of derivatives trading in India was the promulgation of the securities laws (amendments) ordinance, 1995 that withdrew the prohibition on options in securities. The market for derivatives, however, did not take off, as there was no regulatory framework to govern the trading of derivatives, therefore, securities and exchange board of India (SEBI) set-up a 24-member committee under the chairmanship of Dr. L. C. Gupta on $18^{\text {th }}$ of November, 1996 to develop regulatory framework for derivatives trading in India. It prescribed necessary Pre-conditions for the introduction of derivatives trading in India. It recommended that derivatives should be declared as "securities" so that the regulatory framework applicable to the trading of "securities" could also govern trading of derivatives. In this regard the securities and exchange board of India (SEBI) also set up a group under the chairmanship of Prof. J. R. Verma to recommend measures for the risk containment in the derivatives market. Thus, derivatives trading took-off in India after securities and exchange board of India (SEBI) granted the final approval to commence trading and settlement in approved derivatives contracts on the National Stock Exchange (NSE) and Bombay Stock Exchange (BSE). The derivatives trading on the NSE commenced with S\&P CNX Nifty index futures on $12^{\text {th }}$ of June 2000 . The trading in index option commenced on $4^{\text {th }}$ of June 2001 and trading in options on individual securities commenced on $2^{\text {nd }}$ of July 2001. Single stock futures were launched on $9^{\text {th }}$ of November 2001. Today both in terms of volume and turnover, NSE is the largest derivative exchange in India because it has a wide network all over the country. Currently, the derivatives contracts have a maximum of three-month expiration cycles. Three contracts are available for trading, with one-month, two-month and three-month expiry. NSE admits members on its derivatives segment in accordance with the rules and regulation of the exchange and the norms specified by the SEBI, However, the basket of instrument has widened considerably and trading in futures and options is based not only on S\&P CNX Nifty Index but also on other indices viz., CNX IT Index and Banex Index as well as options and futures on individual stocks.

\section{BACK-GROUND OF THE STUDY}

One of the major concerns, regarding the smooth functioning of capital markets, all over the world, is the maintenance of liquidity and volatility at reasonable levels so as to provide more controlled environment to the investors. Indian Capital market is no exception to these crucial concerns that determine the health of every stock market. It was against this back-drop that derivatives were introduced in the Indian capital market on the recommendation of L. C. Gupta Committee. This development was directed to bring about stability that in turn can control volatility.

So for as derivatives are concerned there exists different schools of thought that hold different views, regarding the impact of derivatives on the volatility of the underlying. One school of thought affirms that the presence of derivatives in the capital markets enhances the dissemination of information that brings about efficiency in the flow of information that in turn can take the market towards better levels of efficiency and it is the level of efficiency of the market that determine the level of volatility Kedar Nath Mukherjee and R. K. Mishra (2006). Futures market is beneficial with respect to cash market as it offers better liquidity and also 
lowers long-term volatility of the spot market. The impact cost in the spot market is also influenced by the introduction of derivatives as these products increase the trading volume and liquidity in the cash market James T.W. (1993). These products help in the management of various risks through its diversified product range and they enable the market to absorb risk, otherwise, the cost of risk to the economy would be worse off. They serve as the agents of price discovery that gives direction to the cash market Finnetry and Park (1987). Therefore, it can be concluded that the introduction of derivatives brings about controlled environment in the capital market for the investors with decreased levels of volatility, more liquidity and higher levels of efficiency. In this way they act as catalysts to the growth of capital markets.

The other school of thought holds a different opinion regarding the impact of derivatives on the volatility of the underlying. They hold that derivatives do not reduce risk, even; they expose the users as well as the whole system to new types of risks, the management of which may be more intractable. The existence of derivatives facilitates the speculative waves of buying and selling in the spot market which can cause increase in the volatility of the spot market Lee and Oak (1992). The availability of derivatives may also cause diversion of speculative traders from the cash market to the derivatives market, thus causing a decline in the trading volume/liquidity in the cash market Nathan Associates (1969). Therefore, it is concluded that the argument put forth in favour of derivatives is one-sided, unconvincing and overplayed.

The above discussion regarding the impact of derivatives on the volatility of the underlying is quite inconclusive and do not lead towards a proper conclusion. The two schools of thought are putting forth conflicting opinions about the impact of derivatives on the volatility of the underlying. Therefore, it serves as a source of motivation for the researchers to undertake the present study so as to come up with some findings that can facilitate the existing research literature.

\section{REVIEW OF RESEARCH LITERATURE}

Numerous studies were undertaken on various markets at different time periods to find out the impact of derivatives on the volatility of the underlying. The journey of this research tookoff from its origin in 1975 when Chicago Board of Trade (CBOT) conducted the first study to examine the relationship between option listing and the underlying stock price volatility and the study has revealed that the stock return volatility witnessed a decrease after the introduction of options. This initial finding is supplemented and elaborated by many other studies conducted later on, for example, the study of Dr. M. Thenmozin (2006) concludes that the inception of futures trading has reduced the volatility of spot market. Golaka C. Nath (2004) uses four different models and his findings suggest that the volatility has come down in the post derivatives period.

Skinner (1989) undertakes a study and concludes that option listing is associated with a decline in stock return variances; Cao and H. Henery (1999) study the effect of derivatives assets and one of his conclusions is that introduction of derivatives reduces volatility of the underlying. Sandeep Srivastav (2006) also comes up with the findings that suggest a decline in the level of volatility of underlying.

Fidinia and Grammatikos (1992) in their study conclude that there is a reduction in the variance of stock return following derivatives. Raju and Karande (2003) conclude that the introduction of derivatives brings down the volatility of the underlying asset.

James T.W. (1993) in his study affirms that futures market is beneficial with respect to cash market as it offers better liquidity and also lowers long-term volatility of the spot market. 
Bessember and Segun (1992) provide additional evidence suggesting that active futures markets are associated with the decreased volatility rather than increased volatility.

Darret et al., (1994) examine if futures trading activity has caused stock price volatility. The results affirm that the futures trading have not caused any jump volatility.

However, there are some other studies that are not consistent with regard to the results of the studies that are mentioned above. The studies that come up with conflicting findings are as follows. Nathan Associates (1969) come out with the finding that diversion of speculative interest to the option market may reduce the volume of stock trading and therefore, may cause reduction in the liquidity that might increase volatility.

Hang Chai et al., (1994) examine the impact of futures trading on the liquidity and volatility of the underlying. The results of this study indicate no significant change in volatility of the underlying; however, the trading volume has registered a rise. Aggarwal R.M. (1988) makes a study regarding stock index futures and cash market volatility. The findings of the study confirm that the level of volatility of the post-futures period is more than the pre-futures period.

Jagdesh and Subramanyam (1993) in their study suggest that introduction of index futures does not reduce spread in the spot market and there is weak evidence that spreads might have increased in the post-futures period.

\section{NEED FOR THE STUDY}

A Critical review of the studies referred above brings to fore that these studies suffer from various serious limitations. Some of the studies mentioned in the review do have a very short reference period that makes the results quite vulnerable. For example, the study of Sandeep Srivastav (reference period 2002 November- 2003 February), Kedar Nath Mukherjee and R. K. Mishra (reference period 2004-2006) etc. Such short reference period may become the cause that can lead the study towards some serious errors.

There also exists a fundamental conflict between different studies with respect to the impact of derivatives on the volatility of underlying. Some of the conclusions drawn in the above mentioned studies put forth that derivatives decrease the level of volatility, like Golaka, C. Nath (2004), Skinner (1994), Cao (1999) and Kumar, Saran and Shastri (1998). Contradicting to these findings some of the studies reveal that the introduction of derivatives does not decrease the spread in the spot market. For example, the studies of Hang Chai et al., (1994), Jagdesh and Subramanyam (1993), Nathan Associates (1969) and Darret et al. (1995).

It is against these fundamental deviations in the results as well as the short reference periods that give rise to the need for conducting a detailed study on the subject. The present study entitled "Correlates of Index Futures and spot Index Volatility" is a modest attempt towards this direction. The present study has taken a reasonable reference period so as to arrive at some dependable conclusion.

\section{OBJECTIVES OF THE STUDY}

The present study has been undertaken to achieve the aforesaid objectives.

1. To study the volatility of underlying before the introduction of Index Futures

2. To study the behaviour of volatility in the post derivatives period.

3. To analyze the impact of derivatives on the volatility of the underlying. 


\section{REFERENCE PERIOD}

The present study covers a reference period of four years commencing from 1998 to 2002 . The first two years ( $1^{\text {st }}$ April $1998-31^{\text {st }}$ March 2000) cover the period in which derivatives were not introduced on the index (S\&P CNX NIFTY 50).The period from (1 $1^{\text {st }}$ April $2000-30^{\text {th }}$ September 2000) has been left out so as to exclude the reaction period of spot-market towards the introduction of Index Futures. The next two years ( $1^{\text {st }}$ October $2000-30^{\text {th }}$ September 2002) cover the period in which derivatives were introduced on the index (S\&P CNX NIFTY 50).

\section{Presentation of Reference Period}

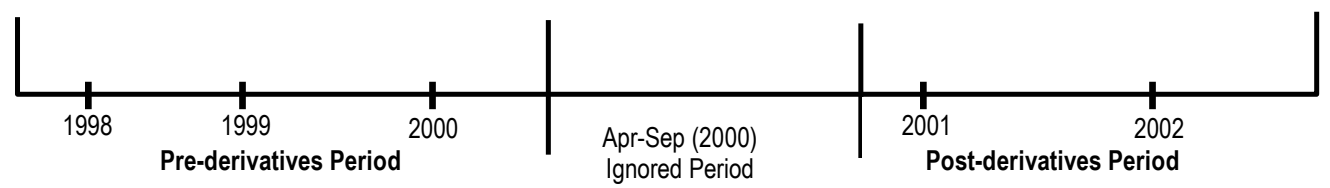

\section{DATA-BASE AND RESEARCH METHODOLOGY}

In order to achieve the objectives of the study, relevant intraday data has been collected from the website of National Stock Exchange. The main data for the study is about S\&P CNX NIFTY (50) spot Index which is divided into two periods, namely, pre-derivatives period and post derivatives period .The daily observations are recorded and then the mean of every day's observation is calculated by taking into consideration the previous close price, open price, high price, low price, last price and close price. The mean of every trading day stands as the representative of that day and is taken as a base to calculate the quarter mean, standard deviation and variance. For the purpose of these calculations the researchers have used SPSS 13.00 package.

The formulas used for the purpose of calculation are given below.

\section{Formula of Standard Deviation $(\sigma)=\sqrt{\Sigma f đ X^{2} / N-(\Sigma f đ / N)^{2} \times I}$ Formula of Variance $=\sigma / \mathrm{X} \times 100$ Formula of Mean $=\Sigma X / N$}

\section{Table on page \# 252}

As reflected in the table 1-1, it is quite evident that the volatility demonstrates inconsistent behavior throughout the pre-derivatives period. The first quarter of the first year records volatility at 54.09 mark in terms of standard deviation, followed by a decline of $35.38 \%$ in the second quarter of the first year, touching the volatility level of 34.95 mark that also stands as the lowest level of volatility throughout the pre-derivatives period. In the third quarter of the first year, the level of volatility moves to 52.50 mark with an increase of $50.21 \%$. This upward trajectory continues in the fourth quarter of the first year as well in which the level of volatility touches 61.40 mark in terms of standard deviation. The first quarter of the second year records a further increase in the level of volatility by $40 \%$, touching 86.00 mark. However, this upward trajectory discontinues in the second quarter of the second year which registers a significant decline in the level of volatility by $47.95 \%$ as the level of volatility touches 44.76 mark. But the third quarter records jump volatility by $157.37 \%$ which continues in the fourth quarter as well which witnesses a further increase of $21.52 \%$, touching 140.00 mark in terms of standard deviation that also stands as the highest level of volatility throughout the pre-derivatives period. The spread of volatility during the pre-derivatives period stands at (34.95-140.00) which is quite high. These figures depict how inconsistent the spot index is, in terms of volatility, during the pre-derivatives period. The average volatility throughout the prederivatives period stands at 73.61 mark in terms of standard deviation. 
The post-derivatives performance of spot index depicts a different picture in comparison to the pre-derivatives results. The first quarter of the first year records volatility at 76.10 mark in terms of standard deviation, followed by a decline in the second quarter by $30.35 \%$, touching 52.40 mark. The third quarter registers jump volatility by $46.90 \%$ and in the same quarter the level of volatility touches 77.00 mark that also stands as the highest level of volatility throughout the post derivatives period. However, the subsequent quarter registers a significant decline by $53.63 \%$, but the first quarter of the second year again takes the level of volatility to 71.20 mark in terms of standard deviation. Thereafter, there exists a downward trajectory. The second quarter of the second year records a decline of $15.02 \%$, touching 60.50 mark. This continues in the third quarter as well that witnesses a decline of $35.53 \%$, followed by a further marginal decline in the last quarter in which the level of volatility touches 34.00 mark in terms of standard deviation that also stands as the lowest level of volatility throughout the post-derivatives period. The spread of volatility throughout the post-derivatives period stands at (34.00-77.00) levels. These figures stand as an evidence that confirm that the level of volatility throughout the post-derivatives period remain at reasonable levels. The average level of volatility throughout the post-derivatives period stands at 55.73 mark in terms of standard deviation.

\section{GRAPHICAL PRESENTATION OF VARIANCE OF S\&P CNX NIFTY (50)}

\section{Graph on page \# 252}

In the above given graph one can see the movements of variance of both pre-derivatives period and post-derivatives period. The graph of both the periods clearly demonstrates that the spread of pre-derivatives periods stands at (1220.00-19863.00) levels, besides the average level of variance during the pre-derivatives period stands at 6628.32 mark while as the spread of variance during the post-derivatives period stands at (1153.20-5927.00) levels, besides, the average level of variance stands at 3395.15 level which is far higher than the post-derivatives period. Therefore, the graph suggests that the level of variance has come down considerably during the post-derivatives period.

\section{CONCLUSION}

This paper seeks to determine if introduction of Index Futures affects the spot index volatility so as to allay some of the concerns that regulatory agencies, researchers and investing community have about derivatives trading. In this regard the study decomposes that there exists a significant correlation between index futures and spot index volatility as the results of the study affirm that the level of volatility has significantly followed downward trajectory throughout the post-derivatives period compared to the pre-derivatives period as the average level of volatility of pre-derivatives period stands at 73.61mark in terms of standard deviation, compared to 55.73 mark of the post-derivatives period, besides, the spread of volatility has shown a significant decline throughout the post-derivatives period that stands at 43.00 mark, compared to pre-derivatives period in which the spread is quite high at 105.05 mark. This stands as evidence that makes an affirmation regarding the argument that the level of volatility has remained under controllable levels after the onset of index futures on S\&P CNX NIFTY (50).

The findings of the present study collaborate with the findings put forth by Bessember and Segun (1992), James T. W. (1993), Fidinia and Grammatikos (1992) and Golaka C. Nath (2004).Thus, the collaboration of the findings of the present study with the findings of the 
above mentioned studies further strengthens the argument that the introduction of futures contracts on the S\&P CNX NIFTY (50) have had a beneficial impact on the spot index volatility.

\section{BIBLOGRAPHY}

Aggarwal, R.M (1988): “Stock Index Futures and Cash Market Volatility”, Review of Futures Markets Volumes, 7, pp. 290-299.

Bessemberder, H and Seguin P.J. (1992): "Futures Trading Activity and Stock Price Volatility", The Journal of Finance, 57(5):2015-2035.

Cao, H Henery (1999): “The Effect of Derivatives Assets on Information Acquisition and Price Behaviour in a Rational Expectation Equilibrium”, Review of Financial Studies, 12:1341-163.

CBOE (1975): Analysis of Volume and Price Patterns in Stock Underlying. CBOT Options from December 30, 1974 to April 30, 1975, Mimeo, Chicago.

Chan, Kalak, Y; Peter Chang, and Wai-ming Fong, (2002): “The Informational Role of Stock and Options Volume”, Review of Financial Studies, 15:1049-1075.

Damodaran, Aswath and Joseph Lim (1991): “The Effects of Option Listing on the Underlying Stocks Return Processes “, Journal of Banking and Finance, 15:647-664.

Darrety et al. (1995): "Has Future Trading Activity Caused Stock Price Volatility?", Journal of Futures Market, (15):537-557.

Dr. M Thenmozhi. (2006): Future Trading, Information and Spot Price Volatility of National Stock Exchange-50 Index Futures Contract. www.nseindia.com

Fidinia and Grammatikos (1992): “Option Trading and Bid-ask Spread of the Underlying Stocks”, Journal of Business, Volume, 65. No. 30.

Finnetry J.E and HYPark (1987). "stock index futures; Does the tail wag the dog? Technical Note, "Financial Analyst Journal 57-61.

Golaka, C. Nath (2004): Behaviour of Stock Market Volatility after Derivatives. www.nsemdza.com

Hang Chai et al. (1994): "The Effects of Index Futures on the Underlying Stock Market”, The Journal of Futures Markets, (14):293-322

Hayes, Samuel L. and Michael, E. Tannenboun (1979): "The Impact of Listed Options on Underlying Shares “, Financial Management, Winter, 72-76.

Jagdesh N. and Avendhar S. (1993): “ Liquidity Effects of the introduction of S\&P 500 Index Futures Contracts on the Underlying Stock” Journal of Business, 66:171187

James, T W. (1993): "How Price Discovery by Futures Impacts the Cash Market", The Journal of Futures Market, 469-496.

Kedar Nath Mukherjee and R. K. Mishra (2006): Lead-Lag Relationship between Equities and Stock Index Futures Market and its Variation Around Information Release, www.nseindia.com

Kumar, Raman; Atulya Sarin and Kuldeep Shastri (1998): “The Impact of Options Trading on the Market Quality of the Underlying Security - An Empirical Analysis “, Journal of Finance, 53:717-732.

Lee Sang Ben and Oak Ki rod (1992) "Relationship between stock index futures listing and structural changes in time-varying. " Journal of futures market, vol. 12, No. 05, Oct, pp. 493-509.

Nathan Associates (1969): Nathan Associates (1969): Public Policy Aspect of a Futures-type Market in Options on Securities.

Skinner, Douglas, J (1989): Option Markets and Stock Return Volatility, Journal of Financial Economics, 23:61-78.

Whiteside, Marry M; William P. Dukes and Patrick M Dunne, (1983): “Short Term Impact of Option Trading on Underlying Securities “, Journal of Financial Research, 6, 4, winter, 313-321. 
TABLE: 1-1.

ANALYSIS OF VOLATILITY OF S\&P CNX NIFTY (50) OF PRE-DERIVATIVES AND POSTDERIVATIVES PERIOD

\begin{tabular}{|c|c|c|c|c|c|c|c|c|c|}
\hline \multirow{2}{*}{$\begin{array}{l}\text { Quarter } \\
\text { Ending }\end{array}$} & \multicolumn{4}{|c|}{ Pre-Derivatives Period } & \multirow{2}{*}{$\begin{array}{l}\text { Quarter } \\
\text { Ending }\end{array}$} & \multicolumn{4}{|c|}{ Post-Derivatives Period } \\
\hline & $\mathrm{N}$ & MEAN & ST.DEV & VAR & & $\mathrm{N}$ & MEAN & ST.DEV & VAR \\
\hline $\begin{array}{c}\text { Q1 } \\
30-06-1998\end{array}$ & 65 & 928.70 & 54.09 & 2713.79 & $\begin{array}{c}\mathrm{Q} 1 \\
31-12-2000\end{array}$ & 63 & 1390.70 & 76.10 & 5800.00 \\
\hline $\begin{array}{c}\mathrm{Q} 2 \\
30-09-1998 \\
\end{array}$ & 63 & 861.60 & 34.95 & 1220.00 & $\begin{array}{c}\mathrm{Q} 2 \\
31-03-2001 \\
\end{array}$ & 63 & 1243.90 & 52.40 & 2745.00 \\
\hline $\begin{array}{c}\text { Q3 } \\
31-12-1998\end{array}$ & 62 & 916.20 & 52.50 & 2757.00 & $\begin{array}{c}\text { Q3 } \\
30-06-2001\end{array}$ & 63 & 1301.00 & 77.00 & 5927.00 \\
\hline $\begin{array}{c}\text { Q4 } \\
31-03-1999\end{array}$ & 63 & 1056.30 & 61.40 & 3776.80 & $\begin{array}{c}\mathrm{Q} 4 \\
30-09-2001\end{array}$ & 62 & 1128.30 & 35.70 & 1275.00 \\
\hline $\begin{array}{c}\text { Q5 } \\
30-06-1999 \\
\end{array}$ & 66 & 1266.60 & 86.00 & 7411.00 & $\begin{array}{c}\text { Q5 } \\
31-12-2001 \\
\end{array}$ & 63 & 1035.60 & 71.20 & 5081.00 \\
\hline $\begin{array}{c}\text { Q6 } \\
30-09-1999\end{array}$ & 63 & 1395.80 & 44.76 & 2003.00 & $\begin{array}{c}\text { Q6 } \\
31-03-2002\end{array}$ & 60 & 1018.00 & 60.50 & 3665.00 \\
\hline $\begin{array}{c}\text { Q7 } \\
31-12-1999 \\
\end{array}$ & 63 & 1574.80 & 115.20 & 13,282 & $\begin{array}{c}Q 7 \\
30-06-2002 \\
\end{array}$ & 62 & 1126.00 & 39.00 & 1515.00 \\
\hline $\begin{array}{c}\text { Q8 } \\
31-03-2000\end{array}$ & 61 & 1461.00 & 140.00 & 19,863 & $\begin{array}{c}\mathrm{Q8} \\
30-09-2002 \\
\end{array}$ & 64 & 1090.20 & 34.00 & 1153.20 \\
\hline
\end{tabular}

Source: Compiled from the website of National Stock Exchange

Graphical Presentation of Variance of S\&P CNX NIFTY (50)

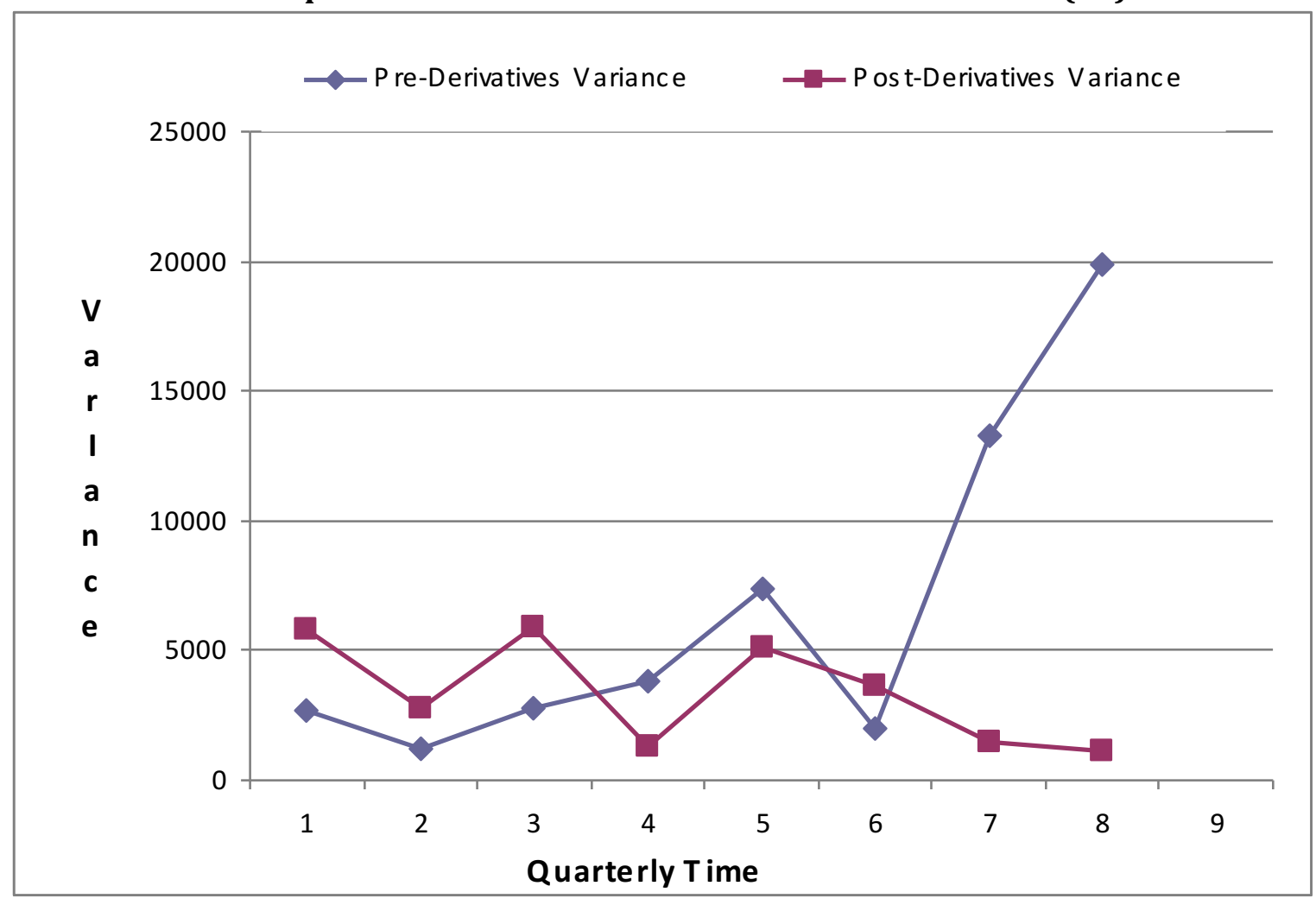

